\title{
A second report on multidrug therapy for leprosy in Trinidad and Tobago
}

\author{
M SUITE \& N B EDINBOROUGH \\ Hansen's Disease Control Unit, Ministry of Health 182 Western \\ Main Road, Cocorite, Trinidad, West Indies
}

Accepted for publication 7 April 1987

\begin{abstract}
Summary Multidrug therapy consisting of rifampicin, clofazimine and dapsone, was introduced to Trinidad and Tobago in January 1982. This was with slight modification of the WHO regimens. Since then 717 patients have completed multidrug therapy up to the end of December 1987. Of these, 272 patients have completed surveillance and have been discharged from clinic attendance. Thirtyfour patients died before completing surveillance and three are known to have migrated. Of the remaining 408 cases still under surveillance, the majority are multibacillary.

This paper reviews the outcome of multidrug therapy in Trinidad and Tobago between January 1982 and December 1987-a period of 6 years, and presents some of the statistics related to the newly diagnosed patients within the same period.
\end{abstract}

\section{Introduction}

Trinidad and Tobago is a twin-island republic situated in the Caribbean Sea, to the north of the South American continent. The country has a population of over one million $(1,059,825)$ by 1980 population census. Trinidad and Tobago launched its programme of multidrug therapy (MDT) in January 1982, using the short course regimens recommended by the World Health Organization (WHO), ${ }^{1}$ with slight modification.

A preliminary report was published in $1984^{2}$ and described the history of antileprosy treatment in Trinidad and Tobago. This report also outlined the approach to the implementation of MDT.

Since there are no facilities for reliably determining drug resistance and because of a concern for compliance at the start, all patients whether paucibacillary (PB) or multibacillary (MB) receive triple therapy. Patients are considered paucibacillary if they are diagnosed clinically or histologically as indeterminate, tuberculoid or borderline tuberculoid on the Ridley-Jopling scale with a bacterial index (BI) of less than 2. Any patients who are diagnosed mid-borderline, borderline lepromatous, or lepromatous on the Ridley-Jopling scale or with a BI of more than 2, are classified as multibacillary.

Paucibacillary patients receive at least 6 monthly doses of $600 \mathrm{mg}$ rifampicin monthly supervised, $300 \mathrm{mg}$ clofazimine monthly supervised and $100 \mathrm{mg}$ daily unsupervised ( $50 \mathrm{mg}$ capsules were unavailable) and $100 \mathrm{mg}$ dapsone daily unsupervised. This regimen is to be completed in 9 months. Newly diagnosed multibacillary patients receive the same drugs for at least 24 monthly 
Table 1. Duration of MDT according to period of bacteriological negativity-MB Patients

\begin{tabular}{lc}
\hline Period of bacteriological negativity & $\begin{array}{c}\text { Duration of MDT } \\
\text { (months) }\end{array}$ \\
\hline 4 years or more & 6 \\
$2-4$ years & 12 \\
2 years or less & 24 minimum \\
New patients & 24 minimum \\
\hline
\end{tabular}

doses and until smear negativity. However, old multibacillary patients were treated according to the period of negativity on the smear examination, as shown in Table 1. Monthly injection of acedapsone (Hansolar) was abandoned in 1984.

At this time there are six outpatient clinics operating. The Hansen's Disease Control Unit was integrated with the Dermatology Unit of the Port of Spain General Hospital in January 1986. This is a 1000-bed hospital with a general admission. Three medical officers of the Dermatology Unit assumed responsibility for the clinics, which became joint Skin-Leprosy Clinics. There is also a medical officer attached to the Control Unit full time. Staff of the Control Unit continue in their specialized roles as district health visitors-nurses (3), medical lab technician (1), follow-up workers (5), medical social worker (1), physiotherapist (1) and shoemaker (1). Their functions have not been integrated into the rest of the primary health care system. Treatment is administered on an outpatient basis.

Paucibacillary patients are placed under surveillance on completing treatment and examined every 6 months for 3 years. Multibacillary patients are examined with slit smear testing at 6 -month intervals for 5 years after completing treatment.

\section{Results}

POST-TREATMENT SURVEILLANCE

Seven hundred and seventeen patients have completed the modified multidrug therapy during the 6year period from January 1982 to December 1987. Three hundred and seventeen were paucibacillary and 400 multibacillary. One hundred and seventy-six patients ( $80 \mathrm{~PB}, 96 \mathrm{MB})$ who were under surveillance up to the end of 1987 have not been seen and therefore are retained on the register. Some of these have been seen on at least one occasion during the surveillance period. Others have never been examined since completing MDT and have not been found or refuse to attend. Many patients seem to believe that completion of treatment implies discharge from clinic.

Two hundred and seventy-two patients have been seen and discharged from surveillance (187 PB, $85 \mathrm{MB}$ ). Fifty-seven patients who entered the surveillance register are known to have died. Of these, 34 died before completing the period of surveillance. Causes of death include complications of diabetes, hypertension, congestive cardiac failure, cerebrovascular accidents and carcinomas. No deaths have been recorded as related to leprosy or chemotherapy.

At least three patients are known to have migrated during the period of surveillance. We suspect however, that many more may have migrated, thereby accounting for failure of attendance. Four hundred and eight cases remain under surveillance, the majority of them are MB cases. 


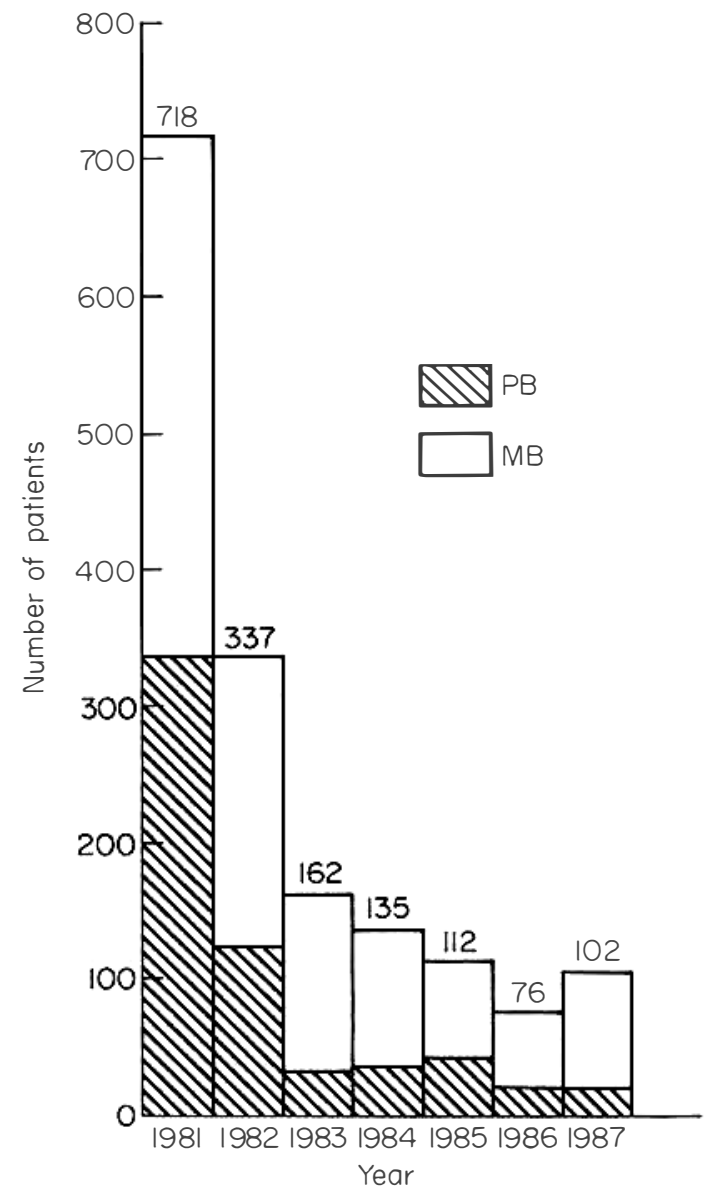

Figure 1. Patients on treatment register at year end.

PATIENTS ON REGISTER

Since MDT was introduced there has been a significant fall in the number of patients on the treatment register. This is shown in Figure 1. The number was practically halved from 1981 to 1982 and then from 1982 to 1983 . There has been only a slight fall in the prevalence rate between 1983 and 1987 (Figure 2).

The marked fall in prevalence between 1981 and 1983 was due to a large number of patients completing the short-term MDT during 1982 and 1983.

The majority of patients registered continue to be over age 15 years. The number of children age 0-14 years registered was significantly reduced from 1981 to 1982 . This is shown in Table 2 . The lowest proportion was registered in $1983(1 \cdot 2 \%)$. In 1985 and 1987 the increase was due to the occurrence of new cases in the child contacts of mainly MB patients. The figures are represented in Figure 3.

In the pre-MDT era, there were as many as $21 \%$ of children $0-14$ years old at the end of 1975 (total patients, 803). 


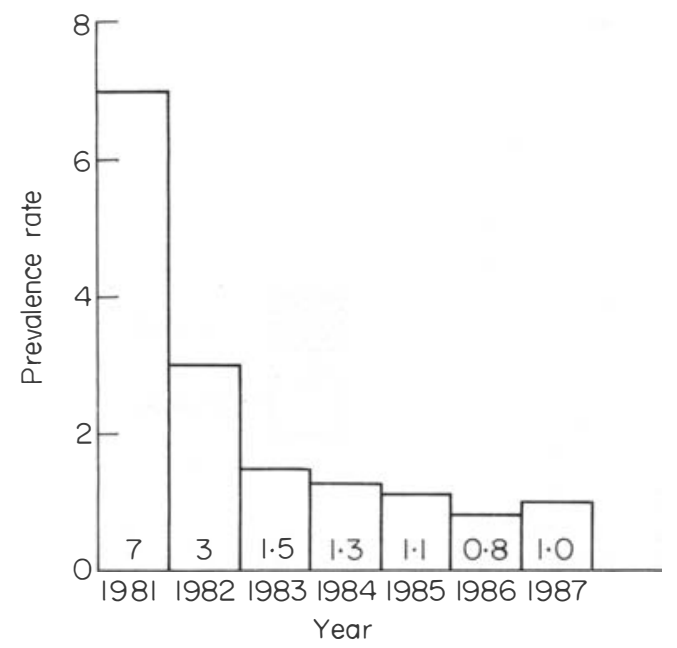

Figure 2. Prevalence rate per 10,000 population.

Table 2. Patients on register by age

\begin{tabular}{lrrrrrrr}
\hline \multicolumn{7}{c}{ YEAR } \\
\hline Age & 1981 & 1982 & 1983 & 1984 & 1985 & 1986 & 1987 \\
\hline $\begin{array}{l}0-14 \text { years } \\
15+\text { Years }\end{array}$ & 56 & 15 & 2 & 3 & 11 & 6 & 11 \\
\hline Total & 718 & 337 & 162 & 135 & 112 & 76 & 102 \\
\hline $0-14$ years $(\%)$ & 8 & 4 & $1 \cdot 2$ & 2 & 10 & 8 & 11 \\
\hline
\end{tabular}

TREATMENT OF MB PATIENTS

Two hundred and fifty M B patients received at least 6 months treatment, 69 received at least 12 doses of MDT and 36 received at least 24 monthly doses. The remaining 45 multibacillary patients (newly diagnosed as well as old patients) had more than 24 months treatment.

\section{ACCEPTABILITY OF TREATMENT}

Regularity of treatment was determined by the proportion of patients taking $75 \%$ of their recommended doses of MDT during the year. A large number of patients completed 6 months of MDT in 1982, many of these being multibacillary patients who were bacteriologically inactive at the time of starting. Regularity is represented in Table 3, and the year immediately prior to MDT is shown for comparison.

There was a fall in regularity in 1983 and 1984 to a level closer to that observed in 1981. However, overall regularity increased in 1985 and has been consistent since then. 


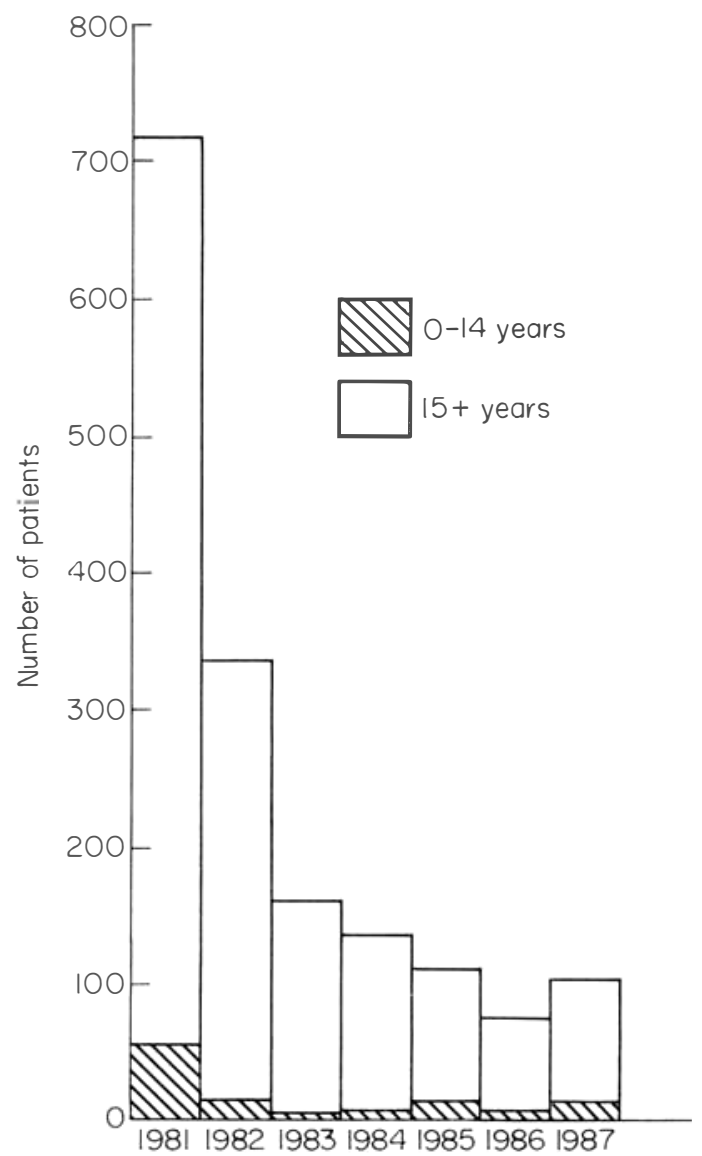

Figure 3. Number of patients on register by age.

Thirty-two patients ref used entirely to accept MDT and were removed from the register. In most instances, the reasons for refusal were not recorded, but some patients believed that the new regimen was experimental and were afraid of possible side-effects. Others believed that they had been cured and did not require further treatment.

Three newly diagnosed MB patients who entered the register during the 6-year period developed sensitivity to dapsone and the drug was discontinued. Two of these had jaundice, erythematous skin

Table 3. Regularity of treatment

\begin{tabular}{lc}
\hline Year & Regularity (Overall) (\%) \\
\hline 1981 & 36 \\
1982 & 75 \\
1983 & 41 \\
1984 & 40 \\
1985 & 63 \\
1986 & 63 \\
1987 & 68 \\
\hline
\end{tabular}


Table 4. Bacteriologically positive patients, 1982-1987

\begin{tabular}{lcc}
\hline Year & $\begin{array}{c}\text { Number of bacteriologically } \\
\text { positive patients }\end{array}$ & Total patients (\%) \\
\hline 1982 & 35 & $10 \%$ \\
1983 & 42 & $26 \%$ \\
1984 & 30 & $22 \%$ \\
1985 & 20 & $18 \%$ \\
1986 & 34 & $45 \%$ \\
1987 & 34 & $33 \%$ \\
\hline
\end{tabular}

rash and fever; one had abdominal pain and vomiting. One has since completed treatment (in 1988) after 36 monthly doses of rifampicin and clofazimine. One TT case with dapsone sensitivity subsequently complained of generalized erythema and swelling within hours of her monthly dose of rifampicin and clofazimine. She completed treatment with clofazimine only and has shown no relapse after 24 months (up to the time of writing).

Of the 102 patients registered at the end of 1987 , four took no treatment in 1986 but two of these resumed in 1987 although irregularly. These patients have ref used drugs on the grounds of religious beliefs and also because they consider that their disease is no longer active.

Eleven of the patients on register at the end of 1987 have had more than 24 months of regular MDT and three of them were still bacteriologically positive at the end of 1987.

\section{BACTERIOLOGICALLY POSITIVE PATIENTS}

The number of bacteriologically positive patients on register at year end has not changed significantly (see Table 4).

The increase in proportion in 1986 was partly due to a proportionally larger number of $\mathrm{MB}$ patients $(16 / 29=55 \%)$ diagnosed in 1986 as compared with $1985(14 / 37=38 \%)$. In addition, more PB (and bacteriologically negative) patients completed treatment during 1986. Many of these were BT patients who had received more than 6 monthly doses because it was felt that 6 months treatment was inadequate and that lesions were still changing. A decision was made to terminate treatment since this did not truly comply with WHO's regimen and did not seem to be justified.

RELAPSES IN PATIENTS COMPLETING TREATMENT

Nineteen patients who have completed the modified MDT between 1982 and 1987 appeared to have relapsed. The details are recorded in Table 5 .

\section{CASE HISTORIES}

Case No. 12. This male patient was diagnosed BB in 1979. He had at the time slit-skin smears showing $3+$ of AFB. He received rifampicin for 3 months and daily lamprene and dapsone when the diagnosis was made. He received 24 months of regular MDT and became smear negative. Seventeen months after completing he presented with clinical reactivation of the old lesions. A skin biopsy showed 'focal inflammation around appendages and nerves. ZN Negative.' Slit-skin smears were negative. MDT was restarted. He has been repeatedly smear negative and the skin lesions have responded to the repeat course of MDT. 
Table 5. 'Relapses' after modified MDT

\begin{tabular}{|c|c|c|c|c|c|c|c|}
\hline $\begin{array}{l}\text { Case } \\
\text { number }\end{array}$ & $\begin{array}{l}\text { Initial } \\
\text { type }\end{array}$ & $\begin{array}{l}\text { Type on } \\
\text { relapse }\end{array}$ & $\begin{array}{l}\text { Therapy prior } \\
\text { to MDT }\end{array}$ & $\begin{array}{c}\text { No. of } \\
\text { MDT doses }\end{array}$ & $\begin{array}{l}\text { Time to } \\
\text { relapse } \\
\text { (Months) }\end{array}$ & $\begin{array}{l}\text { Smear } \\
\text { result }\end{array}$ & $\begin{array}{l}\text { Biopsy } \\
\text { confirmed }\end{array}$ \\
\hline 1 & BT & BT & No & 9 & 10 & $\mathrm{Neg}$ & Yes \\
\hline 2 & BT & BT & No & 6 & 9 & $\mathrm{Neg}$ & ND \\
\hline 3 & Neural & Neural & No & 6 & 8 & $\mathrm{Neg}$ & ND \\
\hline 4 & BT & BT & No & 6 & 14 & Ref used & Refused \\
\hline 5 & BT & BT & No & 6 & 23 & Neg & Yes \\
\hline 6 & BT & BT & Dapsone & $\begin{array}{l}\text { Irregular } \\
6\end{array}$ & 20 & $\mathrm{Neg}$ & Refused \\
\hline 7 & BT & BT & $\begin{array}{l}\text { Rifampicin } \times \\
3 / 12, \text { dapsone } \\
\text { and lamprene }\end{array}$ & 6 & 42 & $\mathrm{Neg}$ & ND \\
\hline 8 & BT & BT & No & 6 & 5 & $\mathrm{Neg}$ & ND \\
\hline 9 & BT & BT & Dapsone & 6 & 7 & $\mathrm{Neg}$ & ND \\
\hline 10 & BT & BT & $\begin{array}{l}\text { Dapsone and } \\
\text { lamprene }\end{array}$ & 6 & 19 & $\mathrm{Neg}$ & ND \\
\hline 11 & TT & TT & No & 10 & 28 & $\mathrm{Neg}$ & Yes \\
\hline 12 & BB & BB & $\begin{array}{l}\text { Rifampicin } \times \\
3 / 12, \text { dapsone } \\
\text { and lamprene } \\
\text { streptomycin and } \\
\text { isoniazid }\end{array}$ & 24 & 17 & $\mathrm{Neg}$ & Suggestive \\
\hline 13 & LL & LL & $\begin{array}{l}\text { Streptomycin } \\
\text { isoniazid, } \\
\text { dapsone and PAS }\end{array}$ & 6 & 23 & $1+$ & Ref used \\
\hline 14 & LL & LL & $\begin{array}{l}\text { Dapsone and } \\
\text { lamprene }\end{array}$ & 6 & 4 & $2+$ & ND \\
\hline 15 & LL & LL & $\begin{array}{l}\text { Dapsone and } \\
\text { lamprene }\end{array}$ & 13 & 19 & $\mathrm{Neg}$ & ND \\
\hline 16 & BT & BT-BL & No & 18 & 12 & $2+$ & Yes \\
\hline 17 & LL & LL & $\begin{array}{l}\text { Dapsone and } \\
\text { lamprene }\end{array}$ & 6 & 58 & Ref used & Yes \\
\hline 18 & TT & TT & $\begin{array}{l}\text { Dapsone and } \\
\text { lamprene }\end{array}$ & $\begin{array}{c}6 \\
\text { Irregular }\end{array}$ & 32 & $\mathrm{Neg}$ & Yes \\
\hline 19 & $\begin{array}{l}\text { Neural } \\
\text { TT }\end{array}$ & $\begin{array}{l}\text { Neural } \\
\text { TT }\end{array}$ & Dapsone & 14 & 12 & Neg & No \\
\hline
\end{tabular}

ND, Not done.

Case No. 13. This female LL patient was diagnosed in 1938. She had received treatment with dapsone monotherapy but also had streptomycin and isoniazid in the early years. At the time of starting MDT she had been smear negative for 4 years and was on dapsone only. She received 6 regular monthly doses and 23 months later on routine follow up was found to be AFB $1+$ without visible skin lesions. The smears were repeated 3 months later and were still $1+$. She has since completed 24 regular MDT doses and achieved smear negativity. No skin biopsy was performed since she refused the procedure.

Case No. 14. This male LL patient was diagnosed in 1970. He had had past treatment with dapsone, streptomycin, isoniazid and PAS, he was receiving treatment with dapsone daily and lamprene three times weekly when MDT was started in 1982. He was bacteriologically inactive for 8 years when 6 doses of MDT were started. Four months after completing this treatment, he returned with skin lesions and slit-skin smears positive at $2+$. No skin biopsy was performed. He died after 
Table 6. Relapse rates from 1982 to 1987

\begin{tabular}{lcc}
\hline Year & PB patients (\%) & MB patients (\%) \\
\hline 1982 & - & $1 \cdot 1$ \\
1983 & $3 \cdot 4$ & - \\
$1984^{*}$ & 16 & - \\
1985 & - & $2 \cdot 6$ \\
1986 & - & - \\
1987 & - & \\
\hline
\end{tabular}

* Three (3) out of nineteen paucibacillary cases completing in 1984 relapsed.

his 23rd dose of MDT and was still clinically active at the time of death. Death was reported to be due to complications of bronchial asthma.

Case No. 15. This man was diagnosed LL in 1955. He had received dapsone and lamprene in the past and had missed 3 months treatment when MDT was started. He had been smear negative for 2 years and received 13 regular doses of MDT. Nineteen months after completing treatment his skin lesions were noted to have become raised. Slit-skin smears were negative and no biopsy was performed. His treatment was resumed.

Case No. 16. This man was diagnosed BT in 1984. He had a single hypoaesthetic lesion on the right shoulder, multiple enlarged nerves, associated with anaesthesia. A slit-skin smear was negative. During his 6 months of MDT he developed right ulnar neuritis and a left drop foot. Prednisolone was started and MDT continued to a total of 18 monthly doses. Twelve months later he presented with nasal stuffiness and infiltrated facial lesions. There were also hypoaesthestic plaques on the upper arms. A skin biopsy from the arm showed foamy histiocytes and lymphocytes, $\mathrm{ZN}$ negative. Slit-skin smears however were $2+$ from both ear lobes.

We believe that this man is a BT relapse with downgrading to BL.

Case No. 17. This male patient was diagnosed LL in 1936. He had prior treatment with dapsone but was on lamprene only since 1972. When MDT was started there had been an 8-month hiatus in

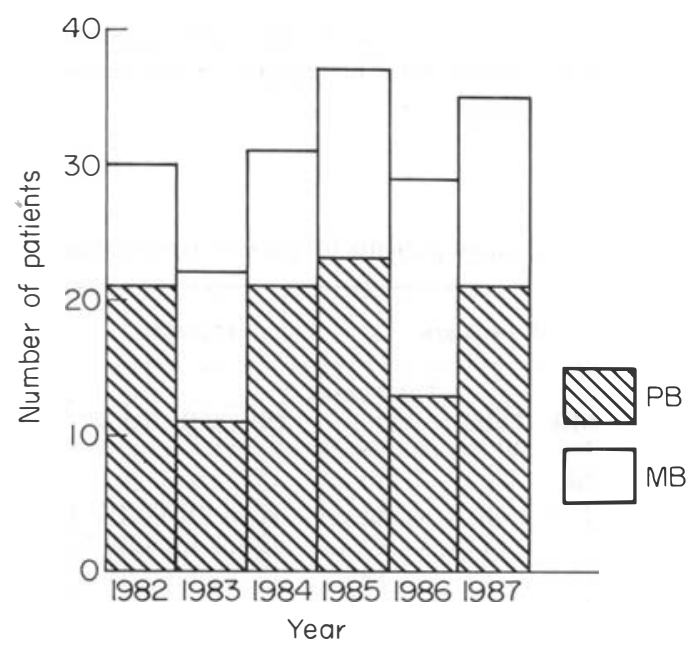

Figure 4. Newly detected cases. 


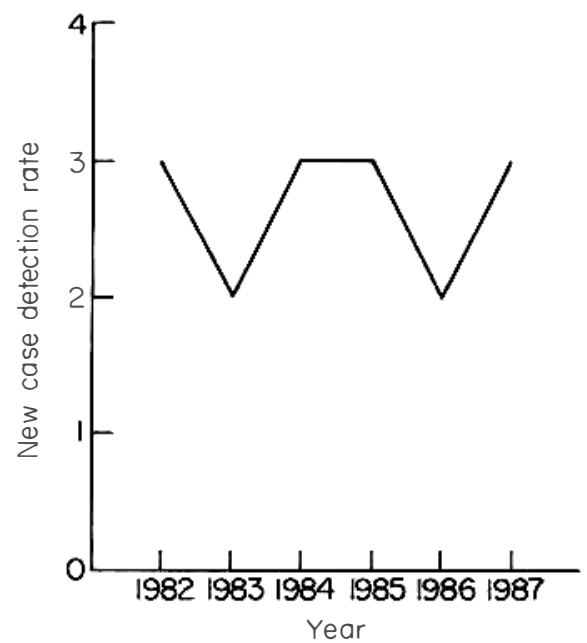

Figure 5. New case detection rate (per 100,000 population).

his treatment. He had been smear negative for 4 years and so he received 6 months of MDT. He presented 2 months before his 5-year surveillance was to end, with skin nodules present for several months. He refused to have slit-skin smears but a skin biopsy showed lepromatous leprosy with numerous acid-fast bacilli. MDT has been resumed.

It is possible that several of the cases were late reactions rather than relapses, e.g. Case Nos 12 and 15. Nine of the paucibacillary cases were not biopsied and therefore suspected relapses were not laboratory confirmed and were treated on the basis of clinical presentation. Eleven out of 14 PB cases $(79 \%)$ were BT and the remaining $21 \%$ TT. We wonder whether this indicates that 6 months of MDT may not be adequate for these patients. Eight out of $14 \mathrm{~PB}$ cases (57\%) were new and had no prior chemotherapy.

The true paucibacillary relapses are probably represented by Case Nos 1, 5, 11 and 18, while Case Nos 14, 16, 17 are true multibacillary relapses. The overall relapse rate for the 6-year period was therefore $1.7 \%$ for paucibacillary patients and $1 \%$ for multibacillary patients. Relapse rates (up to the time of writing) for the years 1982-1987 and based on the year of completion of therapy of the relapsed patients are shown in Table 6. The figures have been calculated separately for paucibacillary and multibacillary groups.

Table 7. Newly detected patients by age and type of disease

\begin{tabular}{|c|c|c|c|c|c|c|c|c|}
\hline \multirow[b]{2}{*}{ Year } & \multicolumn{4}{|c|}{$0-14$ years } & \multicolumn{3}{|c|}{15 years } & \multirow[b]{2}{*}{$\begin{array}{c}\text { Total cases } \\
(\%)\end{array}$} \\
\hline & PB & MB & Total & $\begin{array}{c}\text { Total cases } \\
(\%)\end{array}$ & PB & MB & Total & \\
\hline 1982 & 9 & 0 & 9 & 30 & 12 & 9 & 21 & 70 \\
\hline 1983 & 4 & 1 & 5 & 23 & 12 & 10 & 22 & 77 \\
\hline 1984 & 5 & 0 & 5 & 16 & 12 & 14 & 26 & 84 \\
\hline 1985 & 6 & 1 & 7 & 19 & 17 & 13 & 30 & 81 \\
\hline 1986 & 4 & 1 & 5 & 17 & 9 & 15 & 24 & 83 \\
\hline 1987 & 9 & 1 & 10 & 28 & 12 & 12 & 25 & 72 \\
\hline
\end{tabular}


Table 8. Male to female ratio in new patients

\begin{tabular}{cc}
\hline Year & M:F ratio \\
\hline 1982 & $1 \cdot 7$ \\
1983 & $2 \cdot 1$ \\
1984 & $1 \cdot 4$ \\
1985 & $4 \cdot 3$ \\
1986 & $3 \cdot 1$ \\
1987 & $1 \cdot 1$ \\
\hline
\end{tabular}

Only one of the relapsed BT cases had completed the 3-year surveillance before presenting with apparent relapse. All except two of the others presented within 24 months of stopping treatment (WHO recommends at least 2-year surveillance). The period ranged from five months to 42 months with a mean of 17 months.

Only one of the multibacillary relapses (Case No. 16) had 24 months of MDT. The others were clinically and bacteriologically inactive when MDT was started and received only 6 months of MDT. So far the number of relapses in that group of old patients (i.e. diagnosed before MDT and receiving less than 24 monthly doses) has been low. The regimen administered was contrary to that recommended by WHO and may indicate that 6 months of treatment was inadequate.

\section{NEW PATIENTS}

The number of newly detected cases has remained relatively consistent during the 6-year period. It is difficult to determine a trend for MB $v$ s $\mathrm{PB}$ cases but the proportion of $\mathrm{MB}$ cases has risen from $30 \%$ in 1982 to $40 \%$ in 1987 . The larger proportion of newly detected cases is paucibacillary ranging from $45 \%$ (1986) to $70 \%$ (1982). This is shown in Figure 4.

The new case detection rate had already begun to fall before MDT was introduced from 70 cases and a rate of 6 per 100,000 in 1975 to 25 cases and a rate of 2 per 100,000 in 1981. The rate changed only slightly between 1982 and 1987. This is shown in Figure 5.

The age groups of the newly detected patients according to type of disease are shown in Table 7. The majority of the children ( $0-14$ years) were PB cases however, in the adult group, PB and MB cases were almost equally represented.

Although male patients predominate, the male to female ratio has varied from year to year as is shown in Table 8.

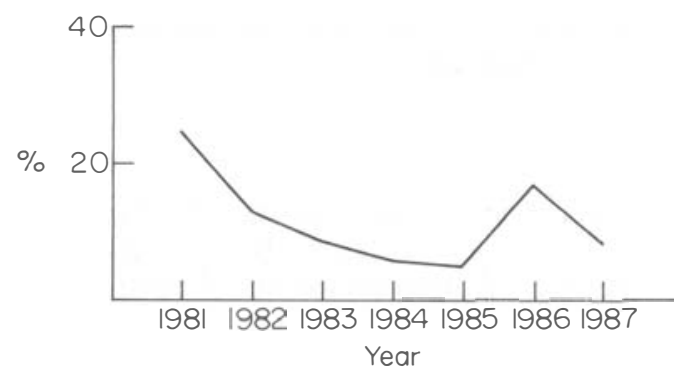

Figure 6. Percentage of new patients with disability greater than or equal to Grade 2 (WHO). 
Table 9. Mode of detection of new patients

\begin{tabular}{lrrrrrr}
\hline Mode of detection* & 1982 & 1983 & 1984 & 1985 & 1986 & 1987 \\
\hline Notification & 20 & 19 & 23 & 23 & 27 & 20 \\
Voluntary & 3 & 0 & 1 & 4 & 0 & 1 \\
Contact survey & 3 & 3 & 7 & 10 & 2 & 12 \\
Group survey (School) & 4 & 0 & 0 & 0 & 0 & 2 \\
\hline Total & 30 & 22 & 31 & 37 & 29 & 35 \\
\hline
\end{tabular}

* No general survey was performed.

\section{DISABILITIES IN NEW PATIENTS}

Disabilities greater than or equal to WHO Grade 2 according to WHO Disability Grading Scale ${ }^{3}$ are infrequent and have been at a low level even bef ore MDT. In 1981 a high of $28 \%$ (seven out of 25 newly detected patients) was recorded. The figure dropped to 5\% in 1985 but rose again in 1986 to $17 \%$. Figure 6 shows the trend in the disability figures.

All of these patients were over 15 years old at the time of presentation. The mean age for this group was 55 years (range 17-90 years). The youngest patient with any disability was 13 years old at presentation (Grade 1). The minimum time from onset of disability to diagnosis was 6 weeks in one BL patient with an ulnar nerve palsy. The maximum was 10 years.

Of the five patients with Grade 2 and 3 disabilities diagnosed in 1986, four out of five had histories of 1-3 years of illness before diagnosis. This, to us, underlines the importance of failure of early diagnosis in the development of disabilities.

\section{REACTIONS}

Overall, it appears that the incidence of reactions is less now, than bef ore MDT was introduced. No figures are available for comparison. There are four MB patients at this time experiencing chronic ENL and receiving treatment with prednisolone and increased dosage of clofazimine.

\section{MODE OF DETECTION OF NEW PATIENTS}

The majority of cases are diagnosed within the Skin-Leprosy Clinics with a few referrals from other physicians. School surveys have been relatively unproductive as a source of new cases and are usually carried out when new cases attending school have been discovered. Table 9 shows the mode of detection. The relatively high figures for contacts in 1985 and 1987 were due to presence of disease in child contacts $(0-14$ years $)$ of index cases.

\section{Conclusion}

We are of the opinion that multidrug therapy, although slightly modified in our situation, has proved successful so far. The drugs are acceptable to the majority of patients. We hear few complaints about clofazimine-induced pigmentation and patients prefer to be receiving effective medication at the expense of a temporary colour change.

At this time, while the number of new cases remains relatively consistent, we plan to continue our vigilance and will persist in our efforts to educate medical personnel and the general public. 


\section{References}

1 WHO Study Group. Chemotherapy for leprosy control programmes. Technical Report Series 675, 1982.

${ }^{2}$ Keeler RF. Multidrug therapy for leprosy in Trinidad and Tobago: a preliminary report. Lepr Rev, 1984; 55: 391-6.

3 WHO Expert Committee on Leprosy. Fourth Report. Technical Report Series 459, 1970. 